\title{
Pediatric spinal cord astrocytomas: a retrospective study of 348 patients from the SEER database
}

\author{
Andrew S. Luksik, BA, ${ }^{1}$ Tomas Garzon-Muvdi, MD, ${ }^{1}$ Wuyang Yang, MD, ${ }^{1}$ Judy Huang, MD, ${ }^{1}$ and \\ George I. Jallo, MD ${ }^{1,2}$ \\ 1Department of Neurosurgery, The Johns Hopkins University School of Medicine, Baltimore, Maryland; and 2Institute for Brain \\ Protection Sciences, Johns Hopkins All Children's Hospital, St. Petersburg, Florida
}

\begin{abstract}
OBJECTIVE Intramedullary spinal cord tumors comprise $1 \%-10 \%$ of all childhood central nervous system neoplasms, with astrocytomas representing the most common subtype. Due to their rarity and poor prognosis, large populationbased studies are needed to assess the epidemiology and survival risk factors associated with these tumors in the hope of improving outcome. The authors undertook this retrospective study to explore factors that may influence survival in pediatric patients with spinal cord astrocytomas.
\end{abstract}

METHODS Utilizing the Surveillance, Epidemiology, and End Results (SEER) database, a prospective cancer registry, the authors retrospectively assessed survival in histologically confirmed, primary spinal cord astrocytomas in patients 21 years of age and younger. Survival was described with Kaplan-Meyer curves, and a multivariate regression analysis was used to assess the association of several variables with survival while controlling for confounding variables.

RESULTS This analysis of 348 cases showed that age (hazard ratio [HR] 1.05, 95\% Cl 1.01-1.09, $p=0.017$ ), nonwhite race (HR 1.74, 95\% Cl 1.11-2.74, $p=0.014$ ), high-grade tumor status (HR 14.67, 95\% Cl 6.69-32.14, $p<0.001)$, distant or invasive extension of the tumor ( $\mathrm{HR} 2.37,95 \% \mathrm{Cl} 1.02-5.49, \mathrm{p}=0.046)$, and radiation therapy $(\mathrm{HR} 3.74,95 \% \mathrm{Cl}$ 2.18-6.41, $\mathrm{p}<0.001$ ) were associated with decreased survival. Partial resection (HR 0.37, 95\% Cl 0.16-0.83, $\mathrm{p}=0.017$ ) and gross-total resection (HR 0.39, 95\% $\mathrm{Cl} 0.16-0.95, \mathrm{p}=0.039$ ) were associated with improved survival.

CONCLUSIONS Younger age appears to be protective, while high-grade tumors have a much worse prognosis. Early diagnosis and access to surgery appears necessary for improving outcomes, while radiation therapy has an unclear role. There is still much to learn about this disease in the hope of curing children with the misfortune of having one of these rare tumors.

https://thejns.org/doi/abs/10.3171/2017.1.PEDS16528

KEY WORDS pediatric; spinal cord; astrocytoma; oncology; spine

I NTRAMEDULLARY spinal cord tumors in the pediatric population are rare, comprising around 1\%-10\% of all central nervous system neoplasms in pediatric patients..$^{5,31}$ Their annual incidence is less than 1 case per 100,000 children per year. ${ }^{11,27}$ The most common subtype is astrocytoma, which has been reported to account for $40 \%-60 \%$ of all intramedullary spinal cord tumors in children. ${ }^{13,24,31}$ Symptoms typically have gradual onset, with pain being the most common presentation. Motor deficits, scoliosis, and even gastrointestinal deficits may be signs of underlying malignancy, and early symptoms may go unnoticed, especially in infants..$^{13}$ Although radical tumor resection was once thought to induce excessive morbidity and thus not performed, with technological advancements it has become the mainstay of treatment, with improved functional outcomes following gross-total resections compared with partial resection. ${ }^{13}$ Severity of neurological deficits at presentation is directly associated with worse outcomes following surgery, emphasizing the importance of early treatment. ${ }^{9}$ The addition of radiation

ABBREVIATIONS AFT = accelerated failure time; HR = hazard ratio; ICD-O-3 = International Classification of Diseases for Oncology, Third Edition; SEER = Surveillance, Epidemiology, and End Results; WHO = World Health Organization.

SUBMITTED September 15, 2016. ACCEPTED January 27, 2017.

INCLUDE WHEN CITING Published online March 31, 2017; DOI: 10.3171/2017.1.PEDS16528. 
and chemotherapy has met with mixed results, and these adjuvant therapies are typically reserved for high-grade or otherwise inoperable tumors.

Despite aggressive treatment of intramedullary astrocytomas in children, these tumors continue to carry a poor prognosis. High-grade astrocytomas are associated with an especially poor outcome, with a median survival around 6 months, while patients with far more common low-grade tumors may live longer than 6 years. ${ }^{27,17}$ Much research has gone into better understanding the dismal outcomes associated with these tumors. Due to the rarity of these neoplasms, most reviews of pediatric intramedullary tumors are retrospective analyses or case studies with small sample sizes. Thus there continues to be a need for clinical studies with larger patient cohorts to assess the epidemiology and survival risk factors associated with these tumors in the hope of optimizing outcomes. In this population-based retrospective study, we sought to explore survival risk factors in nearly 350 pediatric patients with low- and high-grade spinal cord astrocytomas.

\section{Methods}

\section{Study Design and Selection of Patient Cohort}

This is a population-based retrospective study of survival in pediatric patients with spinal cord astrocytomas. We used the Surveillance, Epidemiology, and End Results (SEER) database, which is a prospectively collected cancer registry actively maintained by the National Cancer Institute. Our study used the most recent release of the "Incidence-SEER 18 Registries Research Data and Hurricane Katrina Impacted Louisiana Cases" from the 2015 submission, which contains cases from years 1973-2013. All pediatric patients with first and primary spinal cord (C72.0 and C72.1) astrocytomas classified by International Classification of Diseases for Oncology, Third Edition (ICD-O-3) were included. Given that tumor size information was not included in the 1973-1982 cohort, we excluded all patients enrolled during this time period. Additional exclusion criteria included: not first or primary tumor, no active follow-up (tumor confirmed on autopsy), and diagnosis confirmed by nonhistological modality (radiography, direct visualization, clinical diagnosis, or unknown modality).

\section{Variable Definitions}

Patient age, sex, race, tumor size, extension of tumor, tumor grade, treatment, survival duration in months, and survival status were collected in this study. Age was defined as age at diagnosis, and race was grouped into 4 categories: white, black, Asian, and others or unknown. We classified tumor size, which is recorded as the largest dimension of the lesion in any direction, in 3 categories: < $40 \mathrm{~mm}, \geq 40 \mathrm{~mm}$, and unknown size. The cutoff in tumor size was selected using the mean of all known tumor sizes in this data set. For extension of tumor, 4 categories were included: localized, regional extension, distant or invasive extension, and unknown. These categories are described in the SEER database as follows: a localized lesion refers to a confined lesion; regional extension includes infiltration of dura or surrounding connective/soft tissue; and distant or invasive extension includes involvement of the brain, skull or other bone, major blood vessels, or further contiguous extension. Tumor grade was determined by comparing the ICD-O-3 histology of the tumor with the 2016 version of World Health Organization (WHO) classification of brain tumors. In regard to treatment, extent of resection was classified as no surgery, biopsy only, partial resection, total/gross-total resection, and unknown. Radiation treatment status was dichotomized into whether the patient received radiation therapy or not, but doses of radiation are unknown. Unfortunately, the chemotherapy status of patients is not included in this database. Finally, year of diagnosis was stratified into 3 levels with an interval of 10 years.

\section{Statistical Analysis}

The outcome variable used in this study was survival status, defined as alive or not alive (death from any cause, i.e., all-cause mortality). All of the aforementioned variables were analyzed with respect to survival status. The Student t-test was used for comparison of continuous variables. For categorical variables, the Fisher exact test or chi-square test was used, as appropriate. Survival time was defined as the interval described in months between diagnosis and death or last follow-up reported in SEER. Kaplan-Meier curves were generated for descriptive visualization of survival by different variables. A preliminary all-inclusive multivariate Cox proportional hazard regression revealed violation of the proportional hazard assumption for both race and surgery. Therefore, we used accelerated failure time (AFT) regression, an alternative survival regression model, to fully include all variables and adjust for confounding. Coefficients in the model were converted to hazard ratios for interpretation. Survival rates were calculated for 1-year, 2-year, and 5-year intervals. All p values were reported as 2-sided, with statistical significance defined as $\mathrm{p}<0.05$. Statistical analysis was performed using R statistical software (version 3.2.0, 2013).

\section{Results}

\section{Patient Population and Baseline Demographics}

Over the 30-year period between 1983 and 2013, there were 3164 patients recorded in the SEER database with histologically identified, primary spinal cord tumors whose survival time was documented (Fig. 1). Among this population, 348 were pediatric patients (21 years of age or younger at time of diagnosis) with astrocytomas. Baseline characteristics of the entire cohort and stratified by survival status were compared (Table 1). The average age of this population at diagnosis $( \pm \mathrm{SD})$ was $9.3 \pm 6.1$ years, and $57.5 \%$ were male. The majority $(78.2 \%)$ of the population was white, while $12.9 \%$ was black and $7.2 \%$ was Asian. Of these patients, over half $(51.7 \%)$ were diagnosed with spinal cord tumors between 2003 and 2013,30.5\% between 1993 and 2002, and 17.8\% between 1983 and 1992.

With respect to tumor characteristics, $15.5 \%$ were smaller than $40 \mathrm{~mm}$ in maximum diameter and $17.8 \%$ were $40 \mathrm{~mm}$ or larger in size; size was not reported (unknown) in $66.7 \%$ of cases. Most tumors (80.7\%) were localized, while $7.2 \%$ had regional extension and $6.3 \%$ 


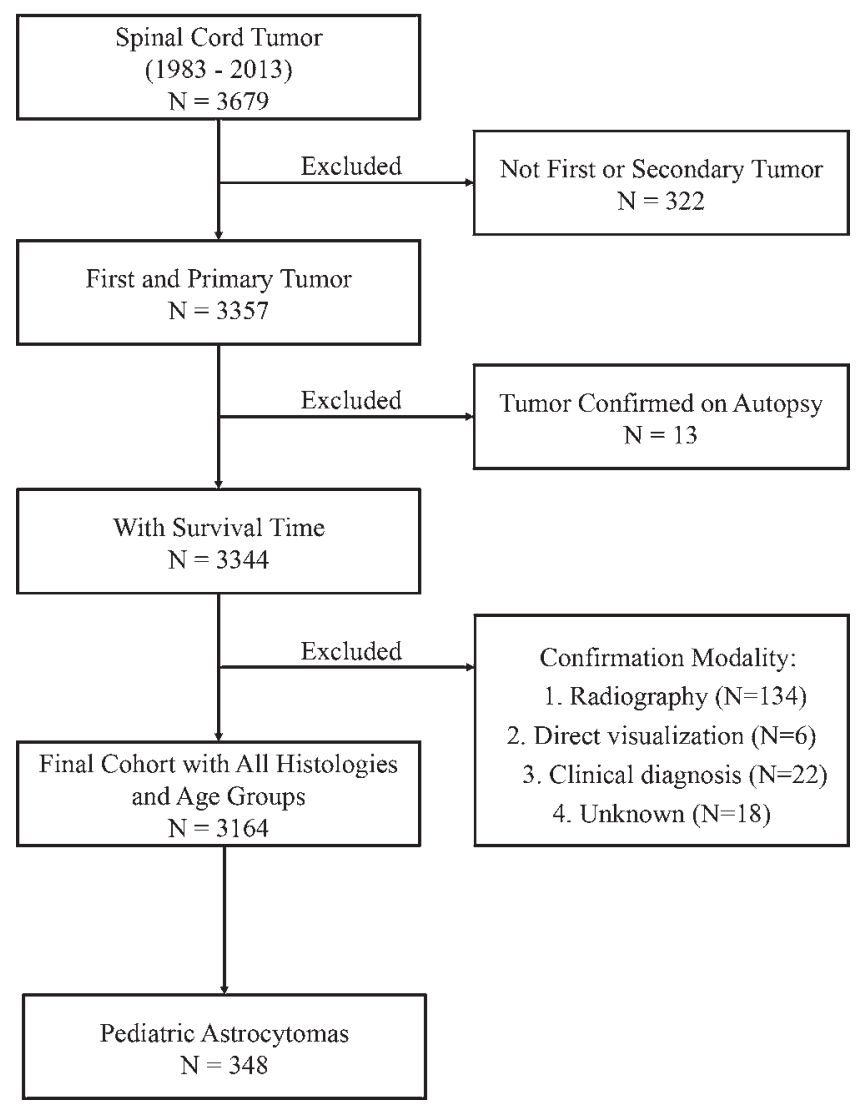

FIG. 1. Flow diagram of patient selection.

had distant extension or invaded surrounding structures. Broken down by WHO classification, 43 (12.4\%) of the tumors were Grade I, 72 (20.7\%) were Grade II, 17 (4.9\%) were Grade III, and 59 (17.0\%) were Grade IV. The tumor grade for $45 \%$ of the patients was not recorded for unclear reasons. The majority of these patients had surgery to decrease tumor burden, with $51.7 \%$ of patients having partial resections and $28.7 \%$ of patients having gross-total resections. Only $28.4 \%$ of this population received radiation therapy. Of the 99 radiated tumors, 49 (49.5\%) were high grade and $16(16.2 \%)$ were low grade (35 had unknown grade).

At the time of data collection, 251 patients were alive and 97 were deceased.

After stratifying by survival status, age $(\mathrm{p}<0.001)$, tumor extension $(\mathrm{p}=0.043)$, surgery status $(\mathrm{p}=0.002)$, radiation therapy $(\mathrm{p}<0.001)$, and year of diagnosis $(\mathrm{p}=$ 0.015 ) were significantly different between these 2 groups.

\section{Survival Results}

Overall survival at 1 year, 2 years, and 5 years after diagnosis was $85.3 \%, 79.5 \%$, and $74.8 \%$, respectively. Kaplan-Meier log-rank testing showed that older age (Fig. 2A), nonwhite race (Fig. 2B), high tumor grade (Fig. 2C), nonlocalized tumors (Fig. 2D), nonsurgical (Fig. 3), and radiation therapy (Fig. 4) were possibly associated with worse overall survival. On univariate accelerated failure time (AFT) regression, age, race, tumor grade, regional extension of tumor, gross-total resection, and radiation
TABLE 1. Baseline and treatment characteristics of pediatric patients with spinal cord astrocytomas

\begin{tabular}{|c|c|c|c|c|}
\hline Parameter & $\begin{array}{c}\text { Total } \\
(n=348)\end{array}$ & $\begin{array}{l}\text { Patient } \\
\text { Alive } \\
(n=251)\end{array}$ & $\begin{array}{c}\text { All-Cause } \\
\text { Death } \\
(n=97)\end{array}$ & $\begin{array}{c}p \\
\text { Value }\end{array}$ \\
\hline Age in yrs, mean (SD) & $9.3(6.1)$ & $8.4(6.0)$ & $11.8(5.8)$ & $<0.001^{*}$ \\
\hline Sex, $n(\%)$ & & & & 0.506 \\
\hline Female & $148(42.5)$ & $104(41.4)$ & $44(45.4)$ & \\
\hline Male & $200(57.5)$ & $147(58.6)$ & $53(54.6)$ & \\
\hline Race, n (\%) & & & & 0.126 \\
\hline White & $272(78.2)$ & $204(81.3)$ & $68(70.1)$ & \\
\hline Black & $45(12.9)$ & $28(11.2)$ & $17(17.5)$ & \\
\hline Asian & $25(7.2)$ & $15(6.0)$ & $10(10.3)$ & \\
\hline Other/unknown & $6(1.7)$ & $4(1.6)$ & $2(2.1)$ & \\
\hline Size of tumor, n (\%) & & & & 0.576 \\
\hline$<40 \mathrm{~mm}$ & $54(15.5)$ & $39(15.5)$ & $15(15.5)$ & \\
\hline$\geq 40 \mathrm{~mm}$ & $62(17.8)$ & 48 (19.1) & $14(14.4)$ & \\
\hline Unknown & $232(66.7)$ & $164(65.3)$ & $68(70.1)$ & \\
\hline Tumor extension, $\mathrm{n}(\%)$ & & & & $0.043^{*}$ \\
\hline Localized & $281(80.7)$ & $211(84.1)$ & $70(72.2)$ & \\
\hline Regional & $25(7.2)$ & $13(5.2)$ & $12(12.4)$ & \\
\hline Distant/invasive & $22(6.3)$ & $13(5.2)$ & $9(9.3)$ & \\
\hline Unknown & $20(5.7)$ & $14(5.6)$ & $6(6.2)$ & \\
\hline \multicolumn{5}{|l|}{ Tumor grade, $\mathrm{n}(\%)$} \\
\hline I & $43(12.4)$ & $41(16.3)$ & $2(2.1)$ & \\
\hline II & $72(20.7)$ & $66(26.3)$ & $6(6.2)$ & \\
\hline III & $17(4.9)$ & $6(2.4)$ & $11(11.3)$ & \\
\hline IV & $59(17.0)$ & $14(5.6)$ & $45(46.4)$ & \\
\hline Unknown & $157(45.1)$ & $124(49.4)$ & $33(34.0)$ & \\
\hline Surgery, n (\%) & & & & $0.002^{*}$ \\
\hline None & $29(8.3)$ & $20(8.0)$ & $9(9.3)$ & \\
\hline Biopsy only & $6(1.7)$ & $3(1.2)$ & $3(3.1)$ & \\
\hline Partial & $180(51.7)$ & $129(51.4)$ & $51(52.6)$ & \\
\hline TR/GTR & $100(28.7)$ & 83 (33.1) & $17(17.5)$ & \\
\hline Unknown & $33(9.5)$ & $16(6.4)$ & $17(17.5)$ & \\
\hline Radiation, n (\%) & & & & $<0.001^{*}$ \\
\hline No & $249(71.6)$ & $211(84.1)$ & $38(39.2)$ & \\
\hline Yes & $99(28.4)$ & $40(15.9)$ & $59(60.8)$ & \\
\hline Yr of Dx, n (\%) & & & & $0.015^{*}$ \\
\hline 1983-1992 & $62(17.8)$ & $36(14.3)$ & $26(26.8)$ & \\
\hline 1993-2002 & $106(30.5)$ & $76(30.3)$ & $30(30.9)$ & \\
\hline 2003-2013 & $180(51.7)$ & $139(55.4)$ & $41(42.3)$ & \\
\hline
\end{tabular}

$\mathrm{Dx}=$ diagnosis; $\mathrm{GTR}=$ gross-total resection; $\mathrm{TR}=$ total resection.

* Statistically significant $(p<0.05)$.

therapy each had statistically significant associations with survival (Table 2). After adjusting for the confounding effects of each variable, our multivariate AFT survival analysis showed that age (hazard ratio [HR] 1.05, 95\% CI $1.01-1.09, \mathrm{p}=0.017$ ), nonwhite race (HR $1.74,95 \%$ CI 1.11-2.74, $\mathrm{p}=0.014$ ), high-grade tumor status (HR 14.67, 95\% CI 6.69-32.14, $\mathrm{p}<0.001$ ), distant extension of the tumor (HR 2.37, 95\% CI 1.02-5.49, $\mathrm{p}=0.046$ ), and radia- 
A

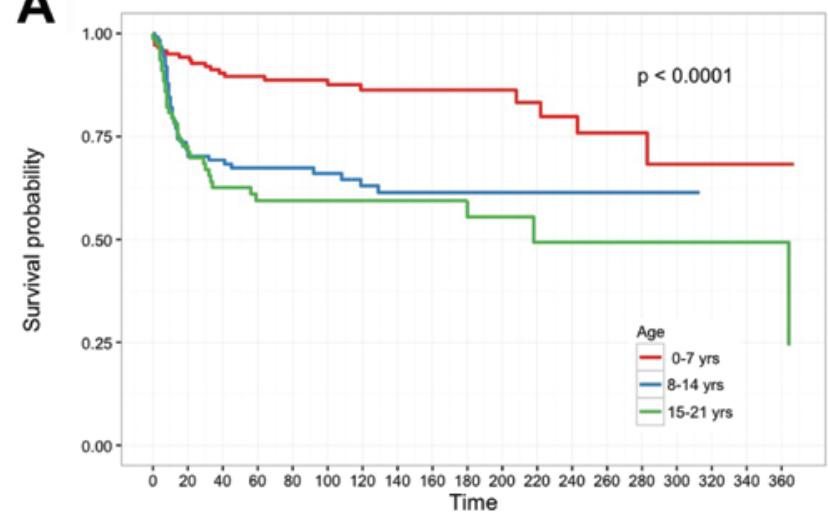

Number at risk by time

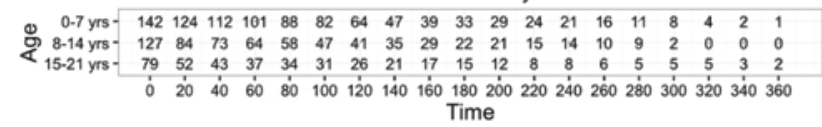

C

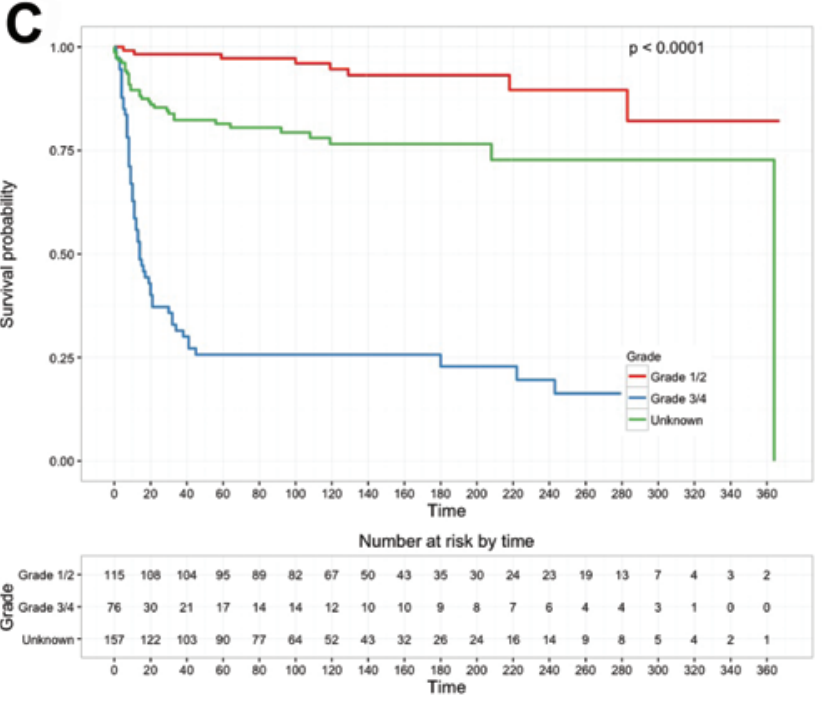

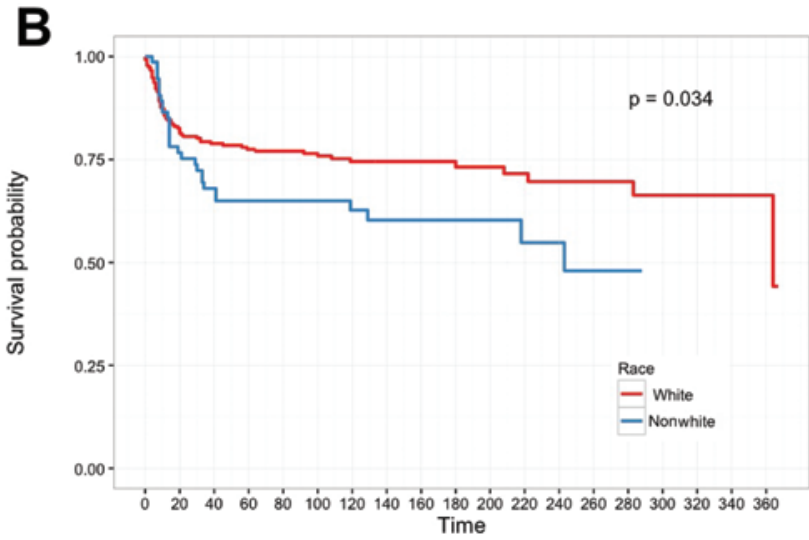

Number at risk by time

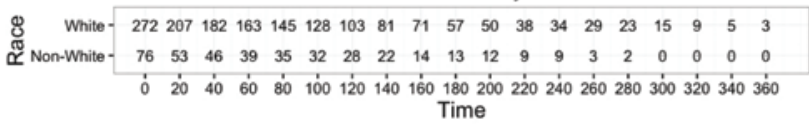

D

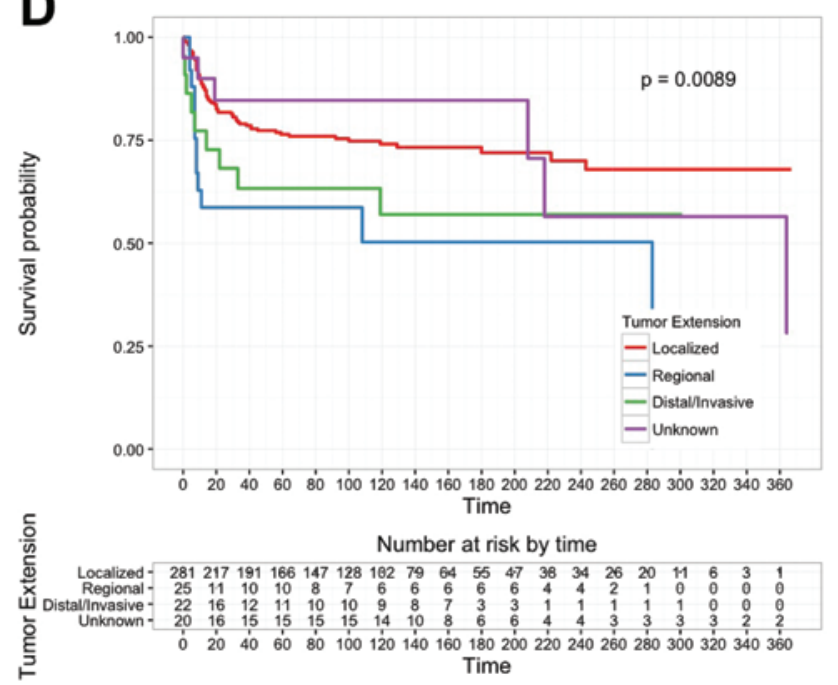

FIG. 2. Kaplan-Meier survival analysis by risk factors. A: Survival by age groups $0-7,8-14$, and $15-21$ years. B: Survival by white and nonwhite race. C: Survival by tumor grade. D: Survival by tumor extension. Time values are in months. Figure is available in color online only.

tion therapy (HR 3.74, 95\% CI 2.18-6.41, p < 0.001) were each associated with worse overall survival. Those who received surgery to decrease tumor burden lived longer, as both partial resection (HR 0.37, 95\% CI 0.16-0.83, p = 0.017 ) and gross-total resection (HR $0.39,95 \%$ CI $0.16-$ $0.95, \mathrm{p}=0.039$ ) were associated with improved survival. While regional extension of tumor had a significant effect on survival in univariate analysis, this effect was lost in multivariate regression (with all factors included). Additionally, partial resection and distant/invasive extension of tumor only showed significant effects on survival in multivariate analysis. Sex, tumor size, and year of diagnosis did not have a statistically significant association with survival outcome in univariate or multivariate analysis.

\section{Discussion}

In an effort to better understand the nature of spinal cord astrocytomas in pediatric patients, we performed a population-based analysis utilizing the SEER database to assess the impact of various factors on survival. To our knowledge, this study of pediatric spinal cord gliomas has the largest sample size to date.

In our study, we saw that older age at time of diagnosis was negatively associated with survival. When patients are grouped by ages $0-7,8-14$, and 15-21 years, Kaplan-Meier curves show the youngest cohort having better survival than both older groups, with 1-year survival rates for the 3 age groups of $95.0 \%, 78.7 \%$, and $78.1 \%$, respectively. The respective 10 -year survival rates for the 3 age groups were $86.3 \%, 63.0 \%$, and $59.4 \%$. This supports previous findings of increased survival in younger children, thought to be due in part to a more beneficial genetic milieu associated with tumor formation in those very young patients compared with those developing tumors at older ages. $22,32,34$ Tumor formation in very young patients may have a different underlying mechanism that 


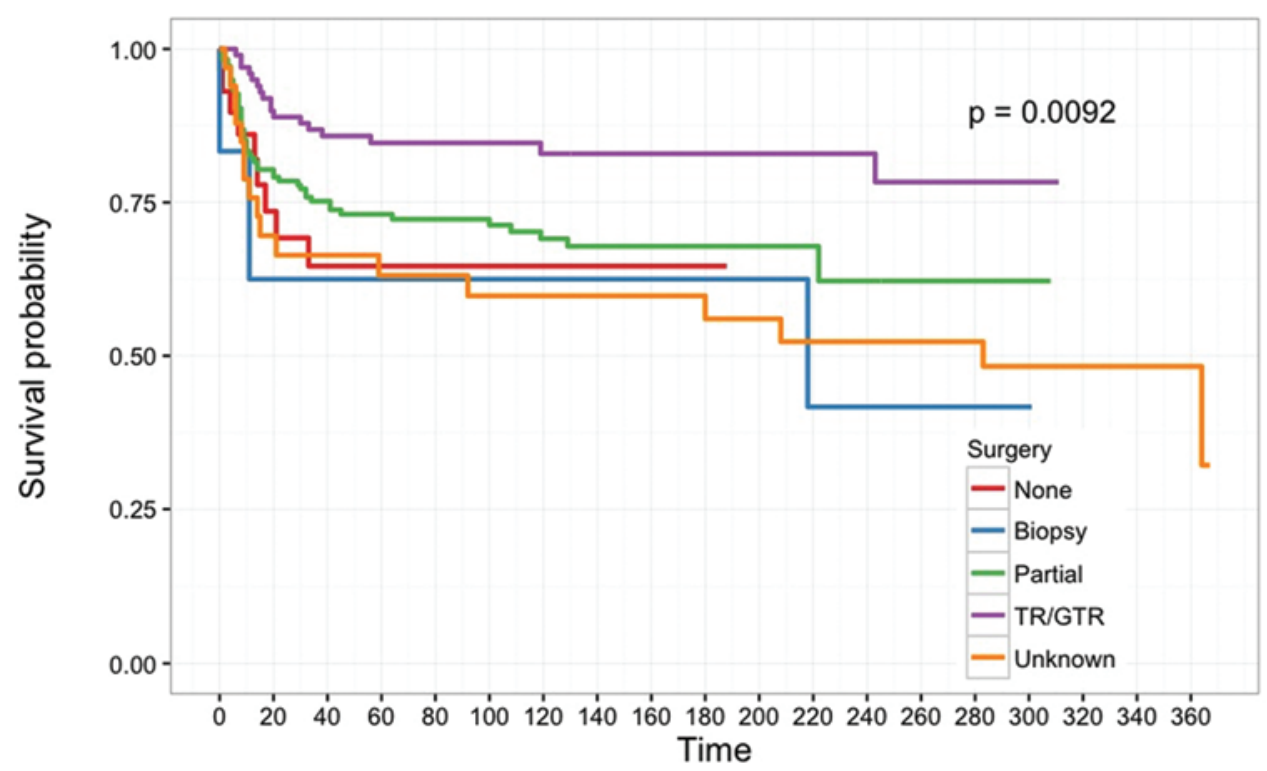

\begin{tabular}{|c|c|c|c|c|c|c|c|c|c|c|c|c|c|c|c|c|c|c|c|}
\hline \multirow{3}{*}{$\begin{array}{rr}\text { None - } & \text { Nond } \\
\text { Biopsy - } \\
\text { Oartial - } \\
\text { OR/GTR - } \\
\text { TR Unknown - }\end{array}$} & \multicolumn{19}{|c|}{ Number at risk by time } \\
\hline & $\begin{array}{c}29 \\
6 \\
180 \\
100 \\
33\end{array}$ & $\begin{array}{c}1.7 \\
3 \\
129 \\
89 \\
22\end{array}$ & $\begin{array}{c}1.3 \\
3 \\
109 \\
82 \\
21\end{array}$ & $\begin{array}{c}12 \\
3 \\
92 \\
76 \\
19\end{array}$ & $\begin{array}{c}10 \\
3 \\
79 \\
69 \\
19\end{array}$ & $\begin{array}{l}6 \\
3 \\
75 \\
58 \\
18\end{array}$ & $\begin{array}{l}5 \\
3 \\
59 \\
47 \\
17\end{array}$ & $\begin{array}{l}3 \\
3 \\
42 \\
39 \\
16\end{array}$ & $\begin{array}{c}2 \\
3 \\
32 \\
32 \\
16\end{array}$ & $\begin{array}{c}1 \\
3 \\
23 \\
27 \\
16\end{array}$ & $\begin{array}{l}0 \\
3 \\
20 \\
24 \\
15\end{array}$ & $\begin{array}{l}\theta \\
2 \\
12 \\
19 \\
14\end{array}$ & $\begin{array}{l}0 \\
1 \\
11 \\
18 \\
13\end{array}$ & $\begin{array}{c}0 \\
1 \\
5 \\
13 \\
13\end{array}$ & $\begin{array}{c}0 \\
1 \\
5 \\
6 \\
13\end{array}$ & $\begin{array}{c}0 \\
1 \\
2 \\
1 \\
11\end{array}$ & $\begin{array}{l}0 \\
\theta \\
0 \\
0 \\
9\end{array}$ & $\begin{array}{l}\theta \\
\theta \\
0 \\
0 \\
5\end{array}$ & $\begin{array}{l}\Theta \\
\theta \\
0 \\
0 \\
3\end{array}$ \\
\hline & 0 & 20 & 40 & 60 & 80 & 100 & 120 & 140 & 160 & 180 & 200 & 220 & 240 & 260 & 280 & 300 & 320 & 340 & 360 \\
\hline
\end{tabular}

Time

FIG. 3. Survival by surgical and nonsurgical procedures. Time values are in months. GTR = gross-total resection; TR = total resection. Figure is available in color online only.

is less aggressive in nature than tumors that develop in older children. For instance, some infants with congenital glioblastomas have had improved survival compared with older pediatrics patients, and there is evidence of agedependent mutational burden and oncogene expression in adult glioblastomas. ${ }^{30,32}$ Thus the biological mechanism of tumor development in children of various ages deserves further investigation, as optimal treatment may differ according to patient age and histological biomarkers. Additionally, we saw that nonwhite children had worse survival than their white counterparts. This does not appear to be previously reported with respect to pediatric patients with spinal cord gliomas, possibly due to the lack of power with small patient populations and their lack of diversity.,11,18 Our finding may be due to the disparity in access to health care resources between these 2 populations, because insurance status has been reported as a predictor of survival in adults with glioblastoma; however, socioeconomic status alone does not appear to be associated with worse survival. ${ }^{15,26}$ As described below, early diagnosis and surgical treatment are crucial for optimal outcomes, and thus health care disparities must be considered when working up patients with these tumors.

In comparison with previous reports, this study had a slightly higher proportion of high-grade (WHO Grade III and IV) tumors at $21.9 \%$ than the reported $10 \%-15 \% .2,5$ However, low-grade tumor status may be underreported in this data set given the fact that tumor grade was not reported for just under half of the patients for unclear reasons. Patients with high-grade tumors fared much worse than those with low-grade tumors (WHO Grade I and II) in this study. The 1- and 5-year survival rates for patients with high-grade tumors were $55.8 \%$ and $25.7 \%$, respectively, while those for patients with low-grade tumors were $98.3 \%$ and $97.2 \%$, respectively. Tumor grade (high vs low) was the most robust predictor of survival in our study, consistent with previous studies of intramedullary gliomas. . $^{17,19,21}$ Thus, obtaining tissue for histological interpretation is crucial for determining prognosis. In addition, tumor extension also significantly impacted survival, as patients with distant extension and invasion into surrounding tissues did worse than those whose tumors were localized. Thus, as expected, more aggressive and infiltrative tumors had a worse prognosis. This emphasizes the importance of recognizing these tumors early in the course of the disease so that appropriate treatment is not delayed. ${ }^{4,8}$

Children with spinal cord astrocytomas who had surgery fared better than those who had no surgical procedure or only biopsy. The rates of surgery for high- and low-grade tumors were nearly the same, at $77.6 \%$ and $82.6 \%$, respectively. For the great majority of the patients who did not receive surgery, their physician did not recommend surgery to them. This is presumably due to contraindications to the procedure, either because of highly aggressive tumors or unsafe surgical conditions. However, surgery showed improved outcome when controlling for tumor size, grade, and extension. Although in the past gross-total resection was thought to incur too much neurological damage to be a standard therapy, our data support the current evidence for resection as the mainstay of treatment for improving 

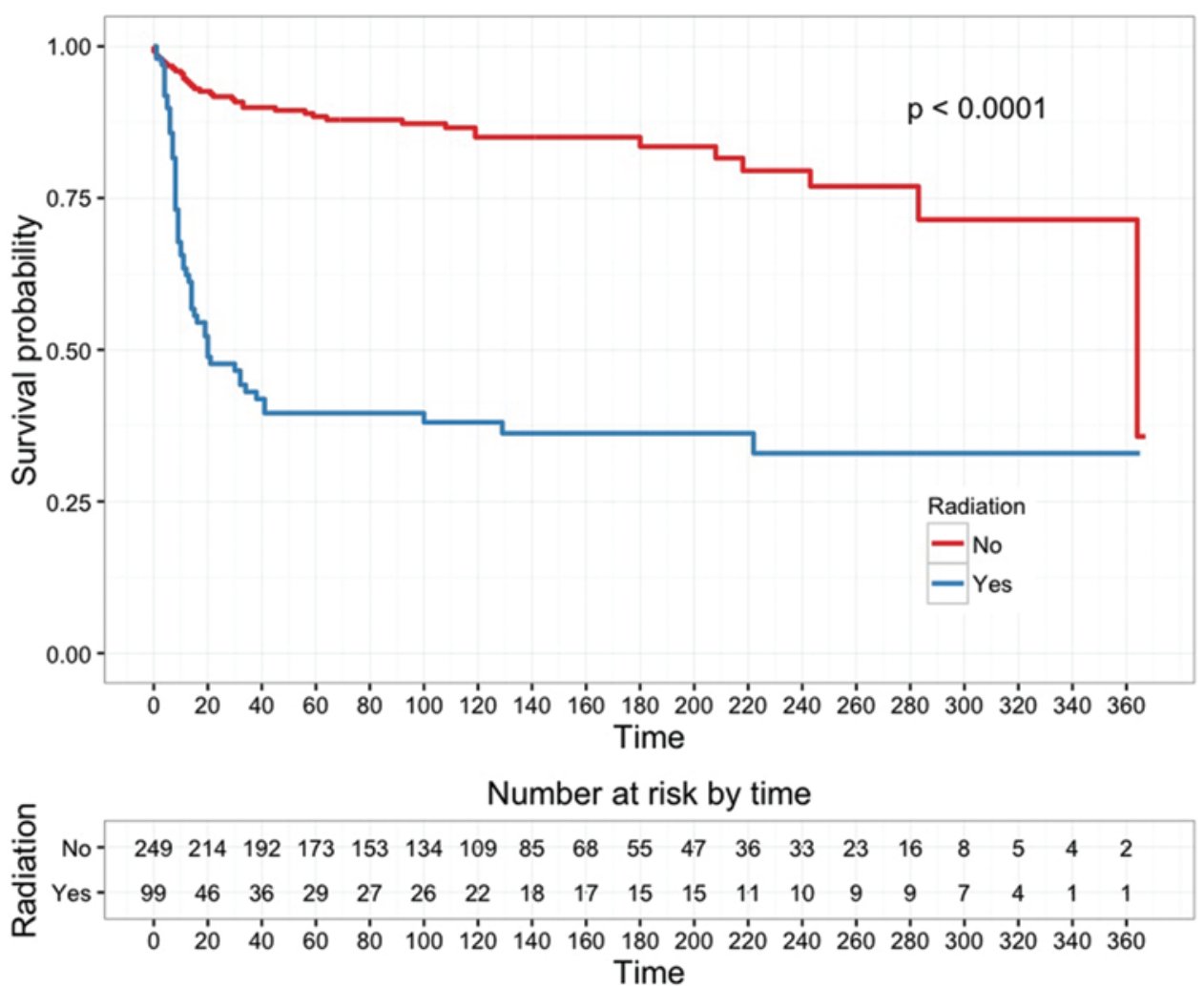

FIG. 4. Survival by radiation therapy status. Time values are in months. Figure is available in color online only.

survival. $^{7-9,13}$ Our data are limited in that pre- and postoperative neurological status is unknown, and thus morbidity due to surgery cannot be measured. However, with improved surgical techniques, imaging, and intraoperative neurological monitoring, patients who have gross-total resection of their intramedullary tumor can expect a quality of life similar to that of matched individuals in the normal population. ${ }^{33}$ Thus this analysis reinforces the importance of early surgical intervention with a goal of maximizing tumor resection with minimal neurological damage.

Radiation therapy was negatively associated with survival in our patient cohort, as those who did not receive radiation treatment lived longer than those who did. Previous studies have revealed mixed findings for the role of radiation as an adjuvant to surgery. While there may be a survival benefit for radiotherapy in the treatment of highgrade or recurrent tumors, there is no clear evidence of benefit for patients with low-grade tumors.,13,24,28,29 The use of radiotherapy prior to surgery may lead to an unfavorable tumor and surgical site for resection, leave the spinal cord more prone to ischemic injury during the operation, and induce myelopathy. ${ }^{35}$ Additionally, radiation may have a deleterious effect on the young, developing nervous system and puts children at risk for secondary cancers. ${ }^{3,11,12}$ Accordingly, in pediatric patients, radiation is typically reserved for more aggressive tumors, tumor recurrence, and contraindications to surgery. ${ }^{10,13}$ In the present study, the majority of patients receiving radiation had high-grade tumors and thus likely had a worse prognosis at baseline. Notably, however, our analysis showed statistically significant reduced survival when we controlled for tumor grade, extension, and surgery status. As tumor recurrence was not recorded in SEER, it is an additional confounding factor for the poor outcomes associated with radiation that we see. The direct effect that radiation itself has on survival cannot be determined from this retrospective study. Although resection, as previously noted, has proven to be a beneficial treatment for these tumors, the role of radiation therapy is still not well established and elicits further study.

There are several limitations to our study, the majority of which are due to limited data collection within SEER. While we were able to select for tumors located within the spinal cord, the exact location was not documented. Although the number of spinal levels involved may not influence survival, specific location might; several studies have shown a trend for thoracic tumors to have improved prognoses when compared with cervical ones, and we could not assess or control for this. ${ }^{16,22,23}$ While treatment with radiotherapy is recorded in the SEER database, it does not document the dosages given. High doses have the potential to reduce tumor recurrence but may actually worsen morbidity and mortality in the developing nervous system. Thus correlating radiation doses with positive and negative outcomes is crucial and could not be done in this study. Furthermore, tumor recurrence was also not recorded in this database but very likely confounds the poor survival seen in the group of patients who received radiation. Another limitation is that the SEER database does not keep a record of the chemotherapy status of patients. We recognize the confounding effect that chemotherapy may have in survival prolongation, and with conflicting evidence for a specific chemotherapy regimen, realize the importance 
TABLE 2. Univariate and multivariate AFT regression of tumor-related survival

\begin{tabular}{|c|c|c|c|c|c|c|}
\hline \multirow[b]{2}{*}{ Parameter } & \multicolumn{3}{|c|}{ Univariate Analysis } & \multicolumn{3}{|c|}{ Multivariate Analysis } \\
\hline & $\mathrm{HR}^{*}$ & $95 \% \mathrm{Cl}$ & $p$ Value & $\mathrm{HR}^{*}$ & $95 \% \mathrm{Cl}$ & $p$ Value \\
\hline Age, per 1 yr increase & 1.08 & $1.05-1.12$ & $<0.001 \uparrow$ & 1.05 & $1.01-1.09$ & $0.017 \dagger$ \\
\hline Sex (male vs female) & 0.86 & $0.58-1.29$ & 0.475 & - & - & - \\
\hline Race (nonwhite vs white) & 1.63 & $1.06-2.53$ & $0.029 \dagger$ & 1.74 & $1.11-2.74$ & $0.014 \dagger$ \\
\hline \multicolumn{7}{|l|}{ Tumor size } \\
\hline$<40 \mathrm{~mm}$ & Ref & - & - & - & - & - \\
\hline$\geq 40 \mathrm{~mm}$ & 0.79 & $0.38-1.64$ & 0.527 & - & - & - \\
\hline Unknown & 0.88 & $0.50-1.54$ & 0.652 & - & - & - \\
\hline \multicolumn{7}{|l|}{ Tumor grade } \\
\hline Low (I \& II) & Ref & - & - & Ref & - & - \\
\hline High (III \& IV) & 22.95 & $10.89-48.47$ & $<0.001 \uparrow$ & 14.67 & $6.69-32.14$ & $<0.001 \uparrow$ \\
\hline Unknown & 4.09 & $1.89-8.86$ & $<0.001 \dagger$ & 4.45 & $2.04-9.70$ & $<0.001 \dagger$ \\
\hline \multicolumn{7}{|l|}{ Tumor extension } \\
\hline Localized & Ref & - & - & Ref & - & - \\
\hline Regional & 2.47 & $1.34-4.55$ & $0.005 \dagger$ & 1.72 & $0.91-3.28$ & 0.098 \\
\hline Distant/invasive & 1.81 & $0.91-363$ & 0.096 & 2.37 & $1.02-5.49$ & $0.046 \dagger$ \\
\hline Unknown & 0.99 & $0.43-2.28$ & 0.974 & 1.12 & $0.46-2.75$ & 0.803 \\
\hline \multicolumn{7}{|l|}{ Surgery } \\
\hline None & Ref & - & - & & & \\
\hline Biopsy only & 1.26 & $0.34-4.69$ & 0.727 & 0.52 & $0.11-2.41$ & 0.401 \\
\hline Partial resection & 0.74 & $0.37-1.50$ & 0.403 & 0.37 & $0.16-0.83$ & $0.017 \dagger$ \\
\hline TR/GTR & 0.34 & $0.15-0.77$ & $0.010 \dagger$ & 0.39 & $0.16-0.95$ & $0.039 \dagger$ \\
\hline Unknown & 1.00 & $0.45-2.27$ & 0.992 & 0.61 & $0.24-1.53$ & 0.288 \\
\hline \multicolumn{7}{|l|}{ Radiation } \\
\hline No & Ref & - & - & Ref & - & - \\
\hline Yes & 5.95 & $3.95-8.96$ & $<0.001 \dagger$ & 3.74 & $2.18-6.41$ & $<0.001 \dagger$ \\
\hline \multicolumn{7}{|l|}{ Yr of Dx } \\
\hline 1983-1992 & Ref & - & - & - & - & - \\
\hline 1993-2002 & 0.78 & $0.46-1.32$ & 0.356 & - & - & - \\
\hline 2003-2013 & 0.96 & $0.58-1.59$ & 0.881 & - & - & - \\
\hline
\end{tabular}

of better understanding its role in the treatment of these tumors. ${ }^{2,14}$ Additionally, evidence from previous studies of smaller cohorts suggests that the rare complication of hydrocephalus is a poor predictor of survival in patients with spinal cord astrocytomas. This outcome was not a recorded variable in the database, and thus we could not assess this association or the prevalence of hydrocephalus in our cohort of patients. ${ }^{6,25}$ It would also have been important to consider the degree of neurological symptoms at presentation, which is not included in this database, as this is a strong predictor of long-term outcome. Finally, there may be patient selection bias in the way data are collected. For instance, healthier patients might be overrepresented in the SEER database (and consequently in this study) if some investigators did not report cases in which they were unable to obtain collateral data due to the patients' poor clinical condition at presentation.

Of note, this database dates back 30 years, and treatment for intramedullary astrocytomas has evolved over that period. As previously mentioned, surgery is currently regarded as the standard treatment. Aggressive resection is thought to yield survival benefits compared with the more conservative approach promoted years ago. ${ }^{13}$ Adjuvant therapies of radiation and chemotherapy have changed, but their role remains unclear. The use of radiation therapy decreased in frequency from $60 \%$ of patients during 1975-1989 to only 30\% during 1990-2007. ${ }^{11}$ Additionally, various chemotherapy regimens have been proposed over the years, mostly drawing from studies of intracranial gliomas; however, due to small sample sizes, there has been no agreed-upon chemotherapy protocol. ${ }^{20}$ Patients who were documented in this study early on certainly may have been treated differently. However, we saw no difference in survival between the 3 decades during which these data were collected.

While randomized clinical trials are the gold standard for clarifying the role of radiation and chemotherapy in treating children with intramedullary astrocytomas, such 
studies are difficult to perform due to the rarity of the disease. Although causality cannot be established due to the retrospective nature of this study, a strength of the study is the increased sample size relative to previously reported analyses. Additionally, data were obtained from multiple centers across the country, making this study population more representative of the general population than the patient cohorts in smaller, single-institution reports. This study confirms many of the findings seen in smaller data sets and further suggests the need for prospective cohort studies to provide improved insight into survival risk factors.

\section{Conclusions}

Our study of 348 pediatric patients with spinal cord astrocytomas provides insight into factors that may influence survival. Younger age appears to be protective, while high-grade tumors have a much worse prognosis. Early diagnosis and improving access to centers with the capabilities for appropriate surgical treatment are necessary for improving outcomes. Radiation therapy has an unclear role in the therapeutic management of these cases. With such a poor prognosis overall, there is still much to learn about this disease in the hope of curing children with the misfortune of having one of these rare tumors.

\section{References}

1. Ahmed R, Menezes AH, Torner JC: Role of resection and adjuvant therapy in long-term disease outcomes for low-grade pediatric intramedullary spinal cord tumors. J Neurosurg Pediatr 18:594-601, 2016

2. Allen JC, Aviner S, Yates AJ, Boyett JM, Cherlow JM, Turski PA, et al: Treatment of high-grade spinal cord astrocytoma of childhood with "8-in-1" chemotherapy and radiotherapy: a pilot study of CCG-945. J Neurosurg 88:215-220, 1998

3. Amirjamshidi A, Abbassioun K: Radiation-induced tumors of the central nervous system occurring in childhood and adolescence. Four unusual lesions in three patients and a review of the literature. Childs Nerv Syst 16:390-397, 2000

4. Arnautovic A, Billups C, Broniscer A, Gajjar A, Boop F, Qaddoumi I: Delayed diagnosis of childhood low-grade glioma: causes, consequences, and potential solutions. Childs Nerv Syst 31:1067-1077, 2015

5. Binning M, Klimo P Jr, Gluf W, Goumnerova L: Spinal tumors in children. Neurosurg Clin N Am 18:631-658, 2007

6. Cinalli G, Sainte-Rose C, Lellouch-Tubiana A, Sebag G, Renier D, Pierre-Kahn A: Hydrocephalus associated with intramedullary low-grade gliomas. Illustrative cases and review of the literature. J Neurosurg 83:480-485, 1995

7. Cohen AR, Wisoff JH, Allen JC, Epstein F: Malignant astrocytomas of the spinal cord. J Neurosurg 70:50-54, 1989

8. DeSousa AL, Kalsbeck JE, Mealey J Jr, Campbell RL, Hockey A: Intraspinal tumors in children. A review of 81 cases. J Neurosurg 51:437-445, 1979

9. Epstein F, Epstein N: Surgical treatment of spinal cord astrocytomas of childhood. A series of 19 patients. J Neurosurg 57:685-689, 1982

10. Guss ZD, Moningi S, Jallo GI, Cohen KJ, Wharam MD, Terezakis SA: Management of pediatric spinal cord astrocytomas: outcomes with adjuvant radiation. Int J Radiat Oncol Biol Phys 85:1307-1311, 2013

11. Hayden Gephart MG, Lober RM, Arrigo RT, Zygourakis CC, Guzman R, Boakye M, et al: Trends in the diagnosis and treatment of pediatric primary spinal cord tumors. J Neurosurg Pediatr 10:555-559, 2012

12. Isaacson SR: Radiation therapy and the management of intramedullary spinal cord tumors. J Neurooncol 47:231-238, 2000

13. Jallo GI, Freed D, Epstein F: Intramedullary spinal cord tumors in children. Childs Nerv Syst 19:641-649, 2003

14. Juthani RG, Bilsky MH, Vogelbaum MA: Current management and treatment modalities for intramedullary spinal cord tumors. Curr Treat Options Oncol 16:39, 2015

15. Kasl RA, Brinson PR, Chambless LB: Socioeconomic status does not affect prognosis in patients with glioblastoma multiforme. Surg Neurol Int 7 (Suppl 11):S282-S290, 2016

16. Konar SK, Maiti TK, Bir SC, Kalakoti P, Bollam P, Nanda A: Predictive factors determining the overall outcome of primary spinal glioblastoma multiforme: an integrative survival analysis. World Neurosurg 86:341-348, 348.e1-348.e3, 2016

17. Kopelson G, Linggood RM: Intramedullary spinal cord astrocytoma versus glioblastoma: the prognostic importance of histologic grade. Cancer 50:732-735, 1982

18. Lam S, Lin Y, Melkonian S: Analysis of risk factors and survival in pediatric high-grade spinal cord astrocytoma: a population-based study. Pediatr Neurosurg 48:299-305, 2012

19. McGirt MJ, Goldstein IM, Chaichana KL, Tobias ME, Kothbauer KF, Jallo GI: Extent of surgical resection of malignant astrocytomas of the spinal cord: outcome analysis of 35 patients. Neurosurgery 63:55-61, 2008

20. Mora J, Cruz O, Gala S, Navarro R: Successful treatment of childhood intramedullary spinal cord astrocytomas with irinotecan and cisplatin. Neuro Oncol 9:39-46, 2007

21. Nakamura M, Chiba K, Ishii K, Ogawa Y, Takaishi H, Matsumoto M, et al: Surgical outcomes of spinal cord astrocy tomas. Spinal Cord 44:740-745, 2006

22. Ononiwu C, Mehta V, Bettegowda C, Jallo G: Pediatric spinal glioblastoma multiforme: Current treatment strategies and possible predictors of survival. Childs Nerv Syst 28:715-720, 2012

23. Raco A, Piccirilli M, Landi A, Lenzi J, Delfini R, Cantore G: High-grade intramedullary astrocytomas: 30 years' experience at the Neurosurgery Department of the University of Rome "Sapienza". J Neurosurg Spine 12:144-153, 2010

24. Reimer R, Onofrio BM: Astrocytomas of the spinal cord in children and adolescents. J Neurosurg 63:669-675, 1985

25. Rifkinson-Mann S, Wisoff JH, Epstein F: The association of hydrocephalus with intramedullary spinal cord tumors: a series of 25 patients. Neurosurgery 27:749-754, 1990

26. Rong X, Yang W, Garzon-Muvdi T, Caplan JM, Hui X, Lim $M$, et al: Influence of insurance status on survival of adults with glioblastoma multiforme: A population-based study. Cancer 122:3157-3165, 2016

27. Schellinger KA, Propp JM, Villano JL, McCarthy BJ: Descriptive epidemiology of primary spinal cord tumors. J Neurooncol 87:173-179, 2008

28. Tendulkar RD, Pai Panandiker AS, Wu S, Kun LE, Broniscer A, Sanford RA, et al: Irradiation of pediatric high-grade spinal cord tumors. Int J Radiat Oncol Biol Phys 78:14511456,2010

29. Townsend N, Handler M, Fleitz J, Foreman N: Intramedullary spinal cord astrocytomas in children. Pediatr Blood Cancer 43:629-632, 2004

30. Watanabe K, Tachibana O, Sata K, Yonekawa Y, Kleihues P, Ohgaki H: Overexpression of the EGF receptor and p53 mutations are mutually exclusive in the evolution of primary and secondary glioblastomas. Brain Pathol 6:217-223, 23-24, 1996

31. Wilson PE, Oleszek JL, Clayton GH: Pediatric spinal cord tumors and masses. J Spinal Cord Med 30 (Suppl 1):S15S20, 2007 
32. Winters JL, Wilson D, Davis DG: Congenital glioblastoma multiforme: a report of three cases and a review of the literature. J Neurol Sci 188:13-19, 2001

33. Wintterle S, Schreiner B, Mitsdoerffer M, Schneider D, Chen L, Meyermann R, et al: Expression of the B7-related molecule B7-H1 by glioma cells: a potential mechanism of immune paralysis. Cancer Res 63:7462-7467, 2003

34. Wolff B, Ng A, Roth D, Parthey K, Warmuth-Metz M, Eyrich $\mathrm{M}$, et al: Pediatric high grade glioma of the spinal cord: results of the HIT-GBM database. J Neurooncol 107:139-146, 2012

35. Xu QW, Bao WM, Mao RL, Yang GY: Aggressive surgery for intramedullary tumor of cervical spinal cord. Surg Neurol 46:322-328, 1996

\section{Disclosures}

The authors report no conflict of interest concerning the materi- als or methods used in this study or the findings specified in this paper.

\section{Author Contributions}

Conception and design: all authors. Analysis and interpretation of data: Jallo, Luksik, Garzon-Muvdi, Yang. Drafting the article: Luksik, Garzon-Muvdi, Yang. Critically revising the article: all authors. Reviewed submitted version of manuscript: all authors. Approved the final version of the manuscript on behalf of all authors: Jallo. Statistical analysis: Yang. Administrative/technical/ material support: Jallo. Study supervision: Jallo, Garzon-Muvdi, Huang.

\section{Correspondence}

George I. Jallo, Johns Hopkins All Children's Hospital Pediatric Neurosurgery, 601 5th St. South, St. Petersburg, FL 33701. email: gjallo1@jhmi.edu. 